\title{
Grasping the rules, highlighting the key points and improving the integral level of normal university's discipline construction
}

\author{
Xuelian Lu \\ Tonghua Normal University Dean's Office, Jilin Province, Tonghua City, 134002, China \\ luxuelian1982@sina.com
}

\begin{abstract}
To grasp the rules, highlight the key points and improve the integral level and quality of normal university's discipline construction, the concrete measures include: correctly handle the relationships between key breakthroughs and integral improvement, the implementation of requirement and long-term development, the discipline construction and scientific research, fundamental and applied research; To optimize and reorganize the research direction, highlight the characteristics of discipline, guarantee the all-round development and relative stability of discipline; To reinforce the talents team building, train academic leaders, optimize the construction of team, strengthen the academic communication; To optimize management mechanism and process, create a harmonious environment and condition for discipline construction, improve the management level and efficiency of discipline construction.
\end{abstract}

Keywords: Normal University; Discipline Construction; Optimization and Reorganization; Talents Team Building; the Management of Discipline Construction.

\section{把握规律 突出重点 提高高师院校学科建设整体水平}

\author{
陆雪莲 \\ 通化师范学院教务处，吉林通化 中国
}

摘要: 准确把握规律、突出重点环节, 提高高师院校学科建设水平和质量效益, 具体措施有: 正确处理好重点突破与整体提高、实现需求与长远发展、学科建设与科学研究、基础研究与 应用研究的关系; 抓好研究方向优化重组, 突出学科特色、确保学科全面发展及研究方向相 对稳定; 加强学科人才队伍建设, 造就领军型学科带头人、优化学科队伍结构、强化学术交 流; 优化管理机制和过程, 创造和谐的学科建设环境与条件、提高学科建设管理水平与学科 建设效益。

关键词: 高师院校; 学科建设; 优化重组; 人才队伍建设; 学科建设管理

\section{1. 前言}

学科建设是一项长期的、复杂的系统工程, 建设内容包括师资队伍建设, 实验室、图书 及信息资料建设, 教学改革与科研学术环境建设, 学科专业体系建设等, 涉及到院校内部众 多管理部门和外部环境。当前学科的发展已步入到多学科交叉、渗透、嫁接、综合的进程, 新兴、边缘学科不断出现，学科间交叉协同、互补共进的需求也越来越高。

\section{2. 提高高师院校学科建设整体水平的具体措施}

\section{1. 加强学科建设, 妥善处理好四组关系}

正确处理好重点突破与整体提高的关系。在学科建设中要坚持 “突出重点、责众扶持、 分层建设” 的原则, 着力加强代表学科前沿方向、体现师范特色、能为师范院校争取较大荣 誉的重点 “品牌” 学科专业建设, 通过实行重点倾斜、重点扶持、重点突破 ${ }^{[1]}$, 尽快取得成 绩、做出贡献。同时, 还要从整体办学水平提高的需要出发, 以重点建设学科的示范、辐射 
作用带动其他学科有一定的覆盖并为其发展提供必要的支撑。

正确处理好实现需求与长远发展的关系。学科建设必须要以基础教育发展需要为基点, 遵循建设的普遍规律并考虑长远发展问题。在处理现实需求与长远发展的关系上, 既要着眼 提高教学质量、培养高素质教育人才, 建设一批对高师院校意义重大的学科, 为基础教育发 展提供强有力的人才和智力支持; 又要立足形成综合化的学科环境, 把握学科前沿, 加强基 础、交叉和新兴学科建设, 形成结构合理、具有前沿性和前瞻性的学科体系, 努力增强学科 发展后劲, 提高学科可持续发展能力。

正确处理好学科建设与科学研究的关系。学科建设必须以科研项目特别是重大综合性项 目作为支撑。坚持教学与科研并重的学科建设原则 ${ }^{[2]}$, 把教学和科研作为学科建设的两翼, 既不畸重畸轻, 更不偏废。要使学士、硕士、博士三个不同层次人才培养成相辅相成, 连贯 统一, 不仅要靠教学, 也要靠科研的支撑, 教学和科研应当在人才培养及学科建设上更加紧 密地结合起来，真正把高师院校办成 “人才培养的基地、示范创新的基地”。

正确处理好基础研究与应用研究的关系。浓厚的基础研究氛围和强大的基础研究实力, 是一所高水平师范院校可持续发展的根基所在。学院在学科建设中应当对基础研究给予重点 扶持, 瞄准重大基础研究展开工作 ${ }^{[2]}$, 从而促进高师院校学科整体实力和科研水平提升。

\section{2. 加强学科建设, 必须抓好研究方向优化重组}

结合实际, 瞄准前沿, 努力突出学科特色。高师院校的性质决定了高师院校的学科建设 必须主动适应基础教育发展的需要, 适应社会对人才需求的发展, 注意突出高师应用人才培 养特色, 突出不同层次人才培养特色, 突出高师院校承训从师职业应用任务的特色。高师院 校的学科建设必须要与基础教育现代化建设的实际紧密结合起来, 在任教应用的边缘和交叉 中探索新的发展方向, 在不同专业间的相互借鉴和渗透中寻找学科新的生长点, 使学科研究 内容具有鲜明师范特色。

发展优势, 择重扶持, 确保学科全面发展。及时把握本学科领域国内外的研究现状和发 展趋势, 准确评价本学科点的水平与地位, 找出差距, 寻求本学科点最有利的发展空间, 选 准自己最有实力的研究方向, 这样才能形成自己的优势 ${ }^{[3]}$ 。面向多学科多专业的交叉与融合, 构建起系统、综合、集成的从教技能创新试验平台。通过抓学科重点方向、抓重大项目、抓 重点实验室建设, 推动学科的全面发展, 增强学科内在的凝聚力, 形成学科优势。

适应发展, 拓宽口径, 确保研究方向相对稳定。根据学科发展及人才培养的需要, 相对 集中地设立研究方向, 有重点地发展职业应用学科。要充分考虑其科学性、前沿性和稳定性, 调整、优化研究方向, 使其为学术梯队和人才培养提供宽广而自由地创造新工作的空间。凡 是高师院校建设和发展急需的, 即使有困难也要千方百计创造条件积极设立或拓宽; 凡是高 师院校建设不需要的, 即使有条件、有优势, 也不能盲目拓宽。

\section{3. 加强学科建设, 必须加强学科人才队伍建设}

加速培养造就一批领军型学科带头人。确立领军人才、拔尖人才和骨干人才培养目标, 实施人才 “攀登计划” ，加强 “传帮带” 和学科带头人的 “交接班” 工作。抓好选拔和培养， 特别要注重对青年学术带头人这一后备力量的培养, 善于把那些学术水平较高、学术思想活 跃、治学严谨、组织能力强的中青年教师选拔出来、委以重任, 在实践中摔打磨练 ${ }^{[4]}$; 完善 激励体制, 鼓励中青年教师到名校攻读博士学位, 开阔学术视野, 提高学术水平; 筹集专项 经费或设立专项基金，资助中青年教师进行自主性、基础性创新研究。

加速优化学科队伍结构。合理的学科队伍应该有不同知识层次和年龄层次的人员组成, 其中既要有年龄较大的教授 (学科带头人) 、博士学位人员或表现突出的硕士学位人员、不 同学科专业的硕士学位人员、本科毕业人员等。学术队伍结构成长的逐步合理化, 是在长期 的教学科研实践中完成的。学科队伍的成员应该是由教学科研任务联合到一起的, 教学科研 的发展会逐渐显现学科间的内在联系, 应根据学科的内在联系, 按照教师从事科学研究的实 际情况, 组建科学合理的学术梯队。 
加强学术研究和交流, 努力提升学术声誉。首先要鼓励学术创新, 紧盯学术前沿, 敢于 挑战学术权威, 用敏锐的眼光和吃苦精神进行学术创新。其次要加大经费资助, 筹措经费重 点资助教师参加国际国内学术交流, 在国际国内重要期刊上发表学术论文, 举办高层次的学 术活动等。再次要强化政策导向, 强调学术质量第一的观念。最后要增进学术氛围。积极采 取人才 “输入” 和 “输出” 并举 ${ }^{[4]}$ 的学术交流办法, 坚持把增进与其他重点高师院校的学术 交流作为优化办学育人模式、拓宽教学科研视野、提升学术声誉的良好途径。创造条件请进 来, 发挥重点学科的窗口作用; 鼓励支持走出去, 制定学术交流机制; 丰富内部学术活动, 定期开展学术交流活动, 形成浓厚的学术氛围。

\section{4. 加强学科建设, 必须优化管理机制和过程}

坚持 “以人为本” 的办学理念, 创造和谐的学科建设环境。高效的组织管理、强有力的 思想政治教育以及科学规范的制度建设等, 是抓好学科建设的基础。学科建设的好与坏, 与 学科建设的组织和领导密不可分, 处理好学科建设过程中的学术管理与行政领导的关系是关 系到学科能否健康发展的关键。绝大多数学科的负责人都不是院、系、教研室的行政负责人, 没有行政职务, 但在学科建设中又居于管理、协调、组织的主导地位, 对学科建设的作用非 常大。因此, 要努力营造一种尊师重教、尊优重贤的校内环境, 突出教师在学校各项工作中 的主体地位, 充分发挥教师在学科建设中的主导作用。

加大经费投入, 积极改善学科建设条件。学科管理运行的好坏、学科建设实绩如何, 与 经费投入具有很大关系。应摒弃传统的过分强调学校投入观念, 树立以学科自我发展为主、 学校投入为辅的理念, 调动学科带头人和全体学科成员的积极性, 通过申请基金、争取横向 项目或成果转让等方式多渠道筹集资金，不断增强学科内部的 “造血功能”。

加强组织和制度建设, 提高学科建设管理水平。高师院校在组织学科建设与管理运行中, 应当充分发挥校、院 (系) 两级学位评定委员会的作用, 以两级学位委员会为主体, 吸收相 关管理人员参加, 组成校、院 (系) 两级学科建设管理机构, 组织协调本级范围内学科建设 具体事宜。在此基础上建立 “三个机制” : 一是学科建设自我管理机制, 充分发挥专家教授 的主体作用和行政领导的组织保障作用, 提高科学的自我完善、自主发展能力; 二是学科建 设过程管理机制, 加强对学科建设方案的论证, 对建设内容和建设进度实施节点控制, 保证 学科建设按计划稳步推进; 三是学科建设目标管理机制, 制定学科建设质量评估指标体系, 完善考评激励措施, 提高学科建设质量水平 ${ }^{[5]}$ 。

深化研究生教育改革, 提高学科建设效益。学科建设的终极目标是培养高层次人才。人 才培养作为学科建设的重要内容, 既是建设水平的主要标志, 又是建设效益的最直接体现。 面临新世纪新阶段高层次人才培养需要, 高师院校的研究生教育必须紧跟国家研究生教育的 改革步伐, 从招生、培养、学位论文、学位答辩、学位授予以及人才培养质量评估等方面入 手, 加大研究力度, 积极探索新形势下推进研究生教育工作的新方法、新路子, 以适应教育 现代化建设和人才培养需求 ${ }^{[6]}$ 。

\section{3. 结论}

一所高师院校的办学层次与实力, 是由其学科人才队伍的整体水平与综合能力体现的; 一个学科能否持续发展则是有其学科队伍的知识结构和年龄结构决定的。没有高水平的学科 队伍, 就不可能有高水平的学科。院校间的竞争, 归根结底是学科队伍水平的竞争。学科队 伍建设是学科建设的核心, 也是学科能否持续发展的关键。科学管理是学科建设效益的重要 保障。学科建设涉及到高师院校建设的方方面面, 必须采用科学管理的方法, 抓住学科建设 的主要环节, 健全管理机制, 优化管理过程, 努力提高学科建设质量和效益。 


\section{致谢}

感谢吉林省教科规划基金项目 “教师教育专业信息化人才培养体系构建与实践”（项目 编号：GH150426）及学校2016年高等教育教学研究重点基金项目 “基于需求导向的创新型学 前人才培养模式研究”。

\section{References}

[1]. Bing Zuo. The Construction of Major Subject and Its Effects on University's Development[J]. The Development Research on Education, 2008,(13).

[2]. Yan Wei. Reviewing and Thinking about the Development of Key Subject Construction of Our Country's Key Disciplines[J].College Education,2013,(8).

[3]. Zude Zhou. To Advance the College's All-round Development around the Core of Discipline Construction[J]. Higher Education,2006,(1).

[4]. Liang Cai. The Building of Evaluation Mechanism for Choosing, Cultivating and Examining the Academic Leader[J]. The Education Exploration,2010,(5).

[5]. Lin Cui. The Basic Rules for the Management of Discipline Construction in University[J]. The Research and Evaluation of Higher Education, 2010,(2).

[6]. Zhihong Sun. The Study on Management of University's Academic Construction[J]. The Degree and Postgraduate Education,2003,(8). 